\title{
Combined Interventional Treatment of Refractory Chronic Migraine
}

\author{
Alexey G. Voloshin ${ }^{1}$ (D) Irina V. Moiseeva ${ }^{1}$ \\ Accepted: 17 March 2021 / Published online: 31 March 2021 \\ (C) The Author(s) 2021
}

\begin{abstract}
Migraine is one of the main causes of disability in modern world. Treatment of chronic refractory migraine (RCM) would be a challenge even for experienced physician. The aim of this study was to analyze the effect of combination therapy for RCM: greater occipital nerve's (GON) pulsed radiofrequency (PRF) and botulinum toxin injections. We observed 6 female patients, suffering from RCM according to the European Headache Federation criteria. All patients had long history of migraine (5-44 years) with conservative treatment failure (at least three medication groups). Their migraine could be classified as refractory for long period of time (1-10 years). All of our patients passed a combination of PRF and BTA injection as consecutive 1-day treatments. Botulinum toxin type A injections were done in accordance to the PREEMPT protocol, followed by ultrasoundguided PRF of GONs bilateral. The observation period was 6 months after the procedure. We observed a positive response to treatment in all patients with dramatic reduction of pain intensity (from $7 \pm 1$ to $2 \pm 2$ on NRS scale) and significant decrease in the number of headache days (from $22 \pm 5$ to $4 \pm 4$ ) during first month after treatment. Two patients (30\%) were pain free after the treatment until the end of the observation. No adverse effects were registered. Bilateral GON's PRF followed by botulinum toxin therapy as 1-day treatment may be a useful option for the treatment of refractory chronic migraine. These interventional procedures are effective, minimally invasive, inexpensive, safe, and well-tolerated and can be performed on an outpatient basis.
\end{abstract}

Keywords Refractory chronic migraine $\cdot$ GON pulsed radiofrequency - Botulinum toxin injections $\cdot$ Interventional pain treatment . Combined interventional procedures

\section{Introduction}

Migraine is one of the most common neurological diseases in clinical practice [1]. According to the Global Burden of Disease 2016 , migraine is one of the leading causes of disability worldwide. Chronic migraine is one of the most severe forms of migraine and occurs in $8 \%$ of migraineurs [2]. Chronic migraine significantly reduces the quality of life of patients, as they experience at least 15 days with headache per month $(8$ out of 15 days with migraine (with or without aura) for at least three consecutive months [3]. Some individuals suffering from migraine are resistant to guideline-based treatment despite substantial advances in migraine therapy [4]. Refractory chronic migraine $(\mathrm{RCM})$ remains one of the most challenging problems

This article is part of the Topical Collection on Medicine

Alexey G. Voloshin

voloshin.icu@gmail.com

1 Pain Clinic Department, Center of Endosurgery and Lithotripsy (CELT), Moscow, Russia in headache medicine $[5,6]$. In the US headache clinic, $5.1 \%$ of patients with migraine was diagnosed with refractory migraine according to the RHSIS criteria [7].

Botulinum toxin type $\mathrm{A}$ is a protein that inhibits the release of acetylcholine from presynaptic nerve endings and inhibits the release of the calcitonin gene-related peptide and substance $\mathrm{P}[8-10]$.

The use of onabotulinotoxin A (BTA) for migraine headache has been approved. BoNT-A is currently used for migraine prevention in the USA, Australia, India, Brazil, Russia, Canada, and Korea [11]. The effectiveness of BTA for chronic migraine treatment was confirmed in the PREEMPT study. BTA treatment has been shown to reduce the number of headache days per month, reduce the amount of medication consumed, and improve the quality of life. PREEMPT study has demonstrated the safety and good tolerability of the treatment, as well as a low incidence of side effects [12-14].

Pulsed radiofrequency ablation (PRF) was first described by Sluijter in 1997 [15]. This method is based on delivering an electric field and heat impulses to nerves or tissues without damaging these structures. In PRF, short electrical stimulation is used, followed by a long pause phase. In this case, the PRF 
does not produce enough heat to cause structural damage [16]. The proposed PRF mechanism implies that the electric field generated by the PRF can alter pain signals [17]. As far as pain alleviation is concerned, this procedure is known to be effective and safe [18]. PRF has been reported to be effective for various types of headaches, including occipital neuralgia, cervicogenic headache, and intracranial hypotension headache, applied to the great occipital nerve (GON) [19-21].

\section{Objective}

The aim of this study was to analyze the effect of combination therapy for RCM: BTA injections followed by greater occipital nerve's (GON) pulsed radiofrequency (PRF).

\section{Materials and Methods}

\section{Patients}

We observed 6 female patients aged 33-57 years, suffering from refractory chronic migraine (RCM) according to the European Headache Federation criteria [22]. All patients had 5-44 years of migraine history, when RCM duration was 110 years. Patient's demographic and pretreatment data are shown in Table 1. All of the patients have gotten an appropriate medical treatment without any success. At least three prophylactic medications were used from different pharmacologic groups, excluding patients with absolute contraindications. Medication overuse was an exclusion criteria. All patients received BTA injections in past with limited success. All previous injections were done according PREEMPT protocol by different physicians. The last BTA treatment was given to each patient more than 6 months before the first visit to our clinic. No other interventional treatment for migraine was done in past for any patient. Before the treatment, all patients were informed that the procedure was experimental with some potential adverse effects and limited potential benefit. Informed consents were obtained from each patient.

\section{Procedures}

Consecutive 1-day treatment was undertaken: first stepBTA injections (onabotulinum A, Botox®, Allergan). Total dosage of 195 Botox ${ }^{\circledR}$ units was used as it was described in the PREEMPT trial. All patients were given injections at two corrugators, one procerus, four frontalis, eight temporalis, and six occipitalis muscles. All of them received additional injections at 2 temporalis muscle, 2 occipitalis muscle, and 4 in the trapezium according to the follow-the-pain method.

It was technically easier to make BTA injections before PRF treatment. PRF treatment of GONs bilateral was performed with ultrasound guidance. The procedure was done in a special room in aseptic conditions. The patients were maintained in the prone position. We searched the GON using a 6- to $15-\mathrm{MHz}$ linear probe (Logiq P6, General Electric, Seoul, Korea) following the method by Greher et al. [23]. The ultrasound probe was located on the spinous process of $\mathrm{C} 2$ and subsequently moved the probe laterally to identify the obliquus capitis inferior muscle of the neck. The GON was found superficial to the obliquus capitis inferior muscle (Fig. 1). After identifying the GON, the catheter needle (22-gauge 5-mm active tip electrode) was inserted, and the sensory stimulation test was carried out using an RF generator (RFG4, Cosman Medical, Burlington, Massachusetts). The catheter sonographic needles were placed close to the right and left GONs using ultrasound control. The position of each needle was verified using sensory stimulation. Dysesthesia and a tingling sensation at the occipital area appeared in all patients stimulated with voltage less than 0.3 . The PRF treatment was administered at 5- Hz, 5-ms pulse width for $360 \mathrm{~s}$ at $65 \mathrm{~V}$ under the constraint that the temperature of the electrode tips did not exceed $42{ }^{\circ} \mathrm{C}$ (Fig. 2) [24]. The procedure was done without any local anesthetic injection (needle insertion point

Table 1 Patient demographic and clinical characteristics

\begin{tabular}{|c|c|c|c|c|c|c|c|}
\hline № & Age & $\begin{array}{l}\text { Migraine } \\
\text { duration, } y\end{array}$ & $\begin{array}{l}\text { Refractory migraine } \\
\text { duration, } y\end{array}$ & $\begin{array}{l}\text { Number of headache } \\
\text { days per month }\end{array}$ & $\begin{array}{l}\text { Pain intensity, } \\
\text { NRS }\end{array}$ & Therapy & $\begin{array}{l}\text { Previous BTA } \\
\text { injection }\end{array}$ \\
\hline 1 & 51 & 44 & 3 & 18 & 9 & Triptans, TCA, AED, MR & 2 injections \\
\hline 2 & 39 & 22 & 10 & 30 & 7 & $\begin{array}{l}\text { Triptans, TCA, AED, AB, } \\
\text { SNRI, NSAID, SD }\end{array}$ & 4 injections \\
\hline 3 & 33 & 16 & 6 & 25 & 8 & Triptans, AED, AB, SNRI, SSRI, SD & 1 injection \\
\hline 4 & 48 & 30 & 1 & 20 & 6 & $\mathrm{AED}, \mathrm{AB}, \mathrm{SD}$ & 1 injection \\
\hline 5 & 44 & 29 & 2,5 & 22 & 8 & Triptans, TCA, AB, NSAID, COMB & 1 injection \\
\hline 6 & 57 & 19 & 2 & 18 & 5 & Triptans, NSAID, AED, COMB & 1 injection \\
\hline
\end{tabular}

$T C A$ tricyclic antidepressants, $S N R I$ serotonin and norepinephrine reuptake inhibitor, SSRI selective serotonin reuptake inhibitor, $A E D$ antiepileptic drugs, $M R$ muscle relaxant, $N S A I D$ nonsteroidal anti-inflammatory drug, $A B$ beta-adrenoblockers, $S D$ sartan drugs, $C O M B$ combined analgetics 


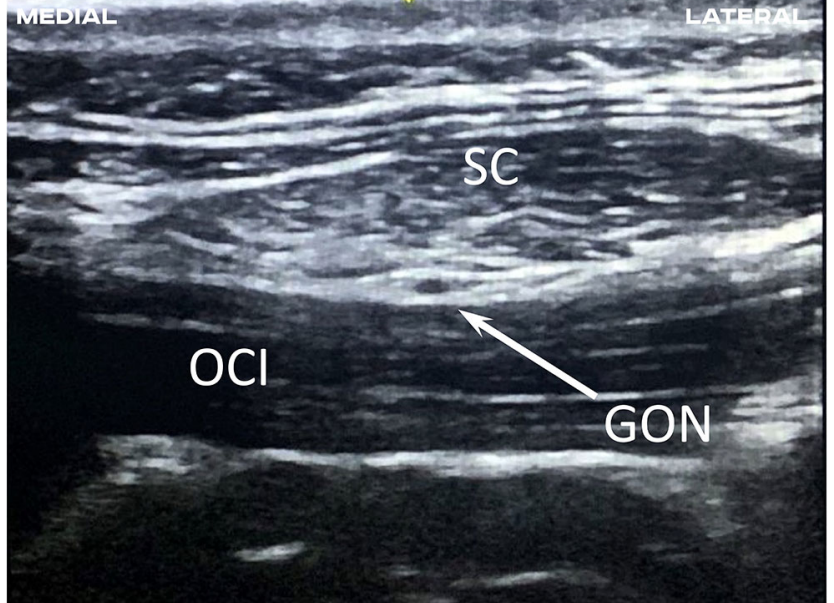

Fig. 1 Transverse ultrasound image of the GON at C2 level. GON arrow $=$ great occipital nerve, $\mathrm{OCI}=$ oblique capitis inferior muscle, $\mathrm{SC}=$ splenius capitis

or treatment point). No other interventional procedures were done for any patient.

Patients remained in the hospital for at least 2-h observation. All of them were discharged home after general and neurological check out.

\section{Outcome Measures}

The observation period after the procedure was 6 months. Every patient reported the outcome monthly (outpatient clinic or phone calls). Pretreatment means headache days, and pain attack intensity was measured with a $0-10$ numeric rating scale (NRS) and compared to post-treatment values.

Statistical analysis was performed using StatPlus for Mac. Continuous variables are presented as mean \pm standard deviation (SD). Within the group, differences were verified using

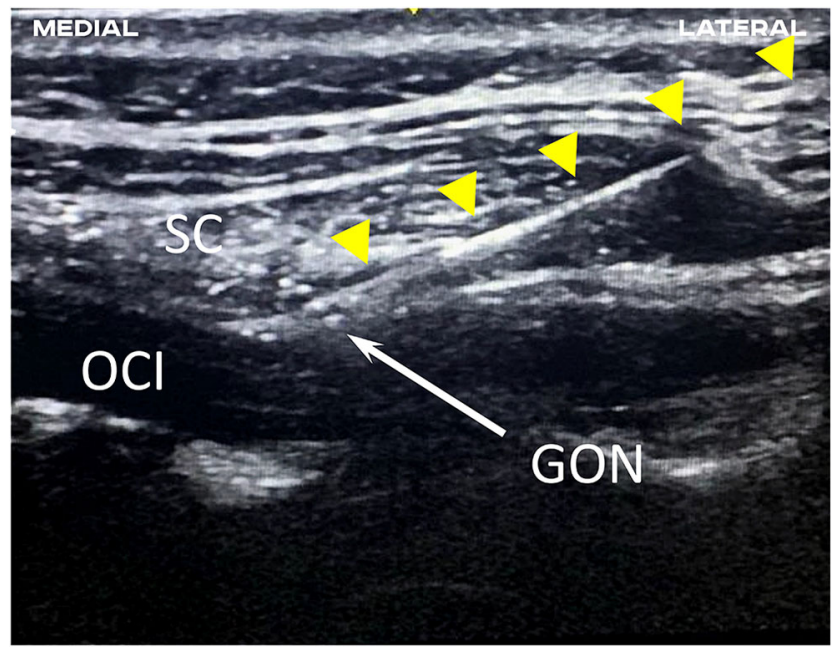

Fig. 2 PRF GON process, transverse ultrasound image. GON arrow = great occipital nerve, $\mathrm{OCI}=$ oblique capitis inferior muscle, $\mathrm{SC}=$ splenius capitis. Arrowheads - canulla the Wilcoxon rank sum test. The level of statistical significance was $\mathrm{P}<0.05$.

\section{Results}

We observed a positive response to treatment in all patients. Mean pain intensity decreased dramatically from $7 \pm 1$ to $2 \pm 2$ on NRS scale (Fig. 3) with significant decrease in the number of headache days from $22 \pm 5$ to $4 \pm 4$ during first month after treatment. Significant positive effect of the treatment was observed up to 6 months after it. Two patients (30\%) stayed pain free after the treatment until the end of observation period (Fig. 4). Some patients halved the dose of daily medication and noticed the appearance of the effect of abortive therapy by triptans and/or NSAIDs (Table 2).

None of the patients had any adverse effects.

\section{Discussion}

The pathophysiology of migraine is complex and is still a focus of research. The main mechanisms of migraine are hypothalamic activation, alteration in thalamo-cortical circuits, altered brain connectivity, brainstem activation, cortical spreading depression, release of CGRP, and PACAP [25].

A pool data analysis from two programs of Phase 3 Research Evaluating Migraine Prophylaxis Therapy (PREEMPT 1 and 2) [14] with BTA in chronic migraine demonstrated significant benefit of BTA over placebo with regard to the numbers of headache days and migraine episodes. However, the effectiveness of botulinum therapy in the treatment of refractory migraine leaves much to be desired. Thus, the effectiveness of botulinum therapy in the treatment of refractory chronic migraine is about 37-50\% [26-28]. With the exception of technical reasons of limited effectiveness (wrong diagnosis or dose of the medication, inappropriate execution of the procedure), the main problem may be low individual susceptibility neutralizing antibody production $[29,30]$.

There are two described clinical cases of GON's PRF for refractory migraine. A young woman in the first report underwent botulinum therapy according to the PREEEMPT protocol at a dose of 155 units and, at the same time, a block of GON. After a negative response, GON's PRF was done with success. Half reduction of pain intensity was shown for least 3 months [24]. Another case described a young 34-year-old woman who suffered from a complex headache, combination of chronic migraine, autonomic cephalgia, and occipital neuralgia. She was treated by $\mathrm{C} 2$ dorsal root ganglion PRF with excellent effect throughout the year [31]. Unfortunately, it is still unclear, whether she suffered mainly from migraine or whether the effectiveness of C2 RFA was associated with its effect on occipital neuralgia. 
30

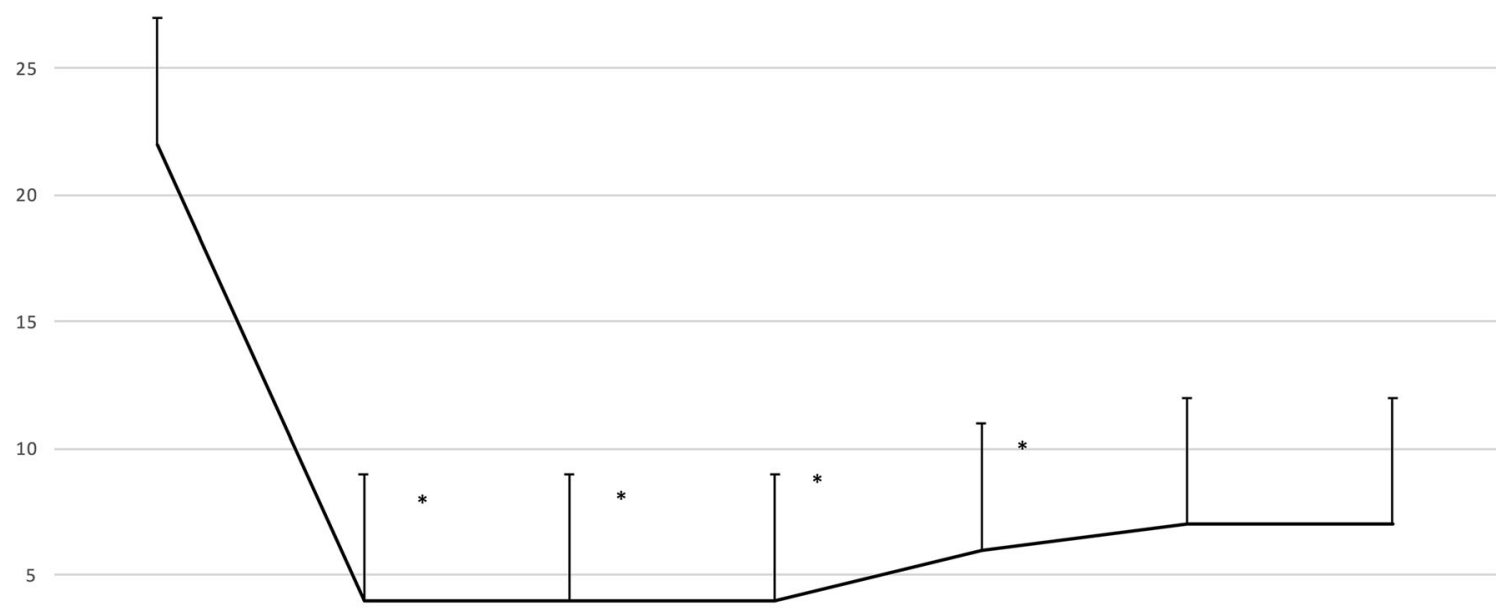

Before treatment $\quad 1$ month $\quad 2$ months 3 months 4 months $\quad 5$ months

Fig. 3 Number of headache days per month (mean $\pm \mathrm{SD}, * p \leq 0.05$ )

PRF is nondestructive procedure. So, GON's PRF could be comparable with GON's block as a kind of enhanced technique [32]. As it was shown by Palamar et al. [33], single injection of a local anesthetic can reduce intensity of pain attacks in RCM patients. Nevertheless, low pain intensity in the study group should be noted (decrease from $3.93 \pm 1.8$ to $1.55 \pm 1.42 \mathrm{~mm}$ VAS). The endpoint in the study was not clear, whether the effect of a single block was change of the number of pain attacks or headache days [33]. In a prospective multicenter study of 84 migraineurs, diagnosed based on IHS 2004, HCCC patients received 4 blocks of GON weekly. Researchers have observed a good effect with reducing the number of headache days from 18 to 9 days a month, as well as reducing the intensity of pain during attacks. It is noteworthy that the decrease in the number of headache days per month was shown in placebo group also (from 17 to 13), with a slight decrease in pain intensity. However, the changes were statistically significant. So, it has been sufficiently convincingly proved that a series of GON blocks with bupivacaine effectively reduces the number of migraine attacks and the intensity of pain. As the study design was cross-sectional,

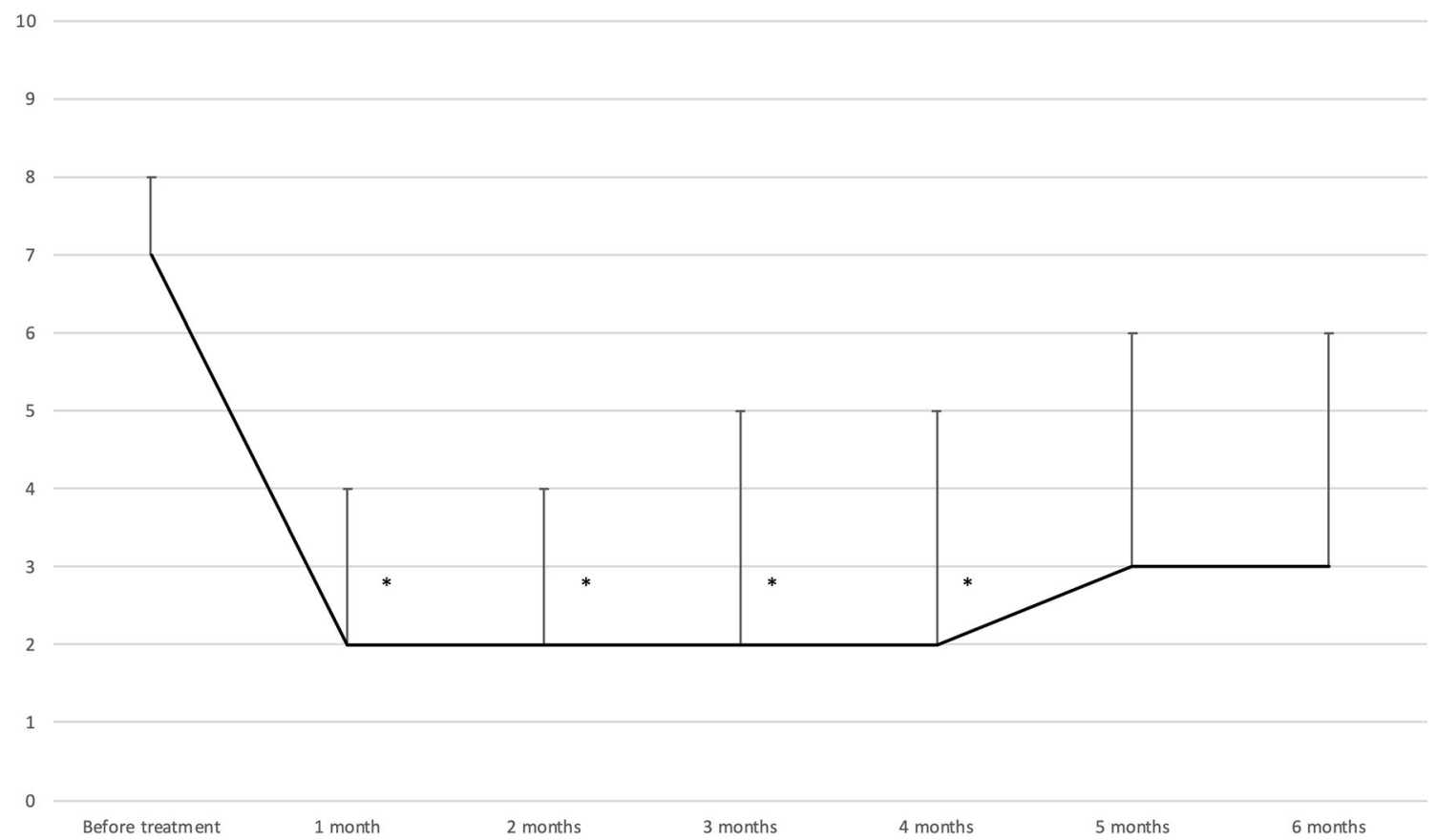

Fig. 4 Pain attack intensity (numeric rating scale, mean $\pm \mathrm{SD}, * p \leq 0.05$ ) 
Table 2 Prophylactic and abortive daily therapy changes

\begin{tabular}{|c|c|c|c|c|}
\hline № & Age & Previous BTA injection & Therapy before & Therapy after \\
\hline 1 & 44 & 1 injections & $\begin{array}{l}\text { - Metoprolol } 100 \mathrm{mg} \\
\text { - Sumatriptan } 200 \mathrm{mg} \\
\text { - Amitriptyline } 100 \mathrm{mg}\end{array}$ & $\begin{array}{l}\text { - NSAID } \\
\text { - Amitriptyline } 25 \mathrm{mg}\end{array}$ \\
\hline 2 & 39 & 4 injections & $\begin{array}{l}\text { - Sertraline } 50 \mathrm{mg} / \mathrm{dul} \text { oxetine } 60 \mathrm{mg} \\
\text { - Topiramate } 100 \mathrm{mg} \\
\text { - Metoprolol } 75 \mathrm{mg} \\
\text { - Candesartan } 16 \mathrm{mg} \\
\text { - Sumatriptan } 200 \mathrm{mg}\end{array}$ & $\begin{array}{l}\text { - NSAID } \\
\text { - Amitriptyline } 100 \mathrm{mg} \\
\text { - Tizanidin } 6 \mathrm{mg}\end{array}$ \\
\hline 3 & 33 & 1 injection & $\begin{array}{l}\text { - Topiramate } 200 \mathrm{mg} \\
\text { - Candesartan } 16 \mathrm{mg} \\
\text { - Sumatriptan } 200 \mathrm{mg} \\
\text { - Sertraline } 100 \mathrm{mg} / \text { duloxetine } 60 \mathrm{mg}\end{array}$ & $\begin{array}{l}\text { - NSAID } \\
\text { - Amitriptyline } 50 \mathrm{mg}\end{array}$ \\
\hline
\end{tabular}

and the treatment group patients received several more GON injections with bupivacaine, it is difficult to estimate how long the treatment effect is [34]. Occipital nerve stimulation is a wellknown kind of neuromodulation for chronic migraine. It is continued to be an off-label treatment because of controversial research results. In a study of 66 patients whose $\mathrm{CM}$ was diagnosed using the second edition of the ICHD-II after a positive response to the test block of GON, the best result was obtained in the group with adjustable neuromodulation. The decrease in the number of headache days was $27 \%$. However, even such a good result, the best among the study groups is still chronic migraine - the decrease was from $22.4 \pm 6.3$ days to $15.7 \pm$ 10.0 days. The percentage of respondents-patients in whom the number of days with a headache decreased by $50 \%$ after stimulation in the best group by adaptive stimulation was 39\% [35].

The main hypothesis of our study is that botulinum toxin reduces peripheral nociceptive afferentation and interrupts the release of inflammatory neuropeptides in the trigeminal complex with a further decrease in neurogenic inflammation of the vessels of the dura mater, which affects the trigeminovascular complex. PRF affects the nonmyelinated (C-fibers) and thinly myelinated (A $\delta$-fibers) axons, participating in the suppression of cortical depolarization through the system of trigeminocervical complex. Therefore, we associate the effectiveness of joint interventional treatment with the simultaneous impact on two main mechanisms of migraine. It can ensure the emergence and maintenance of neurogenic inflammation and cortical spreading depression. Such combined treatment would be a kind of effective neuromodulation of trigeminovascular and trigeminocervical systems.

\section{Conclusion}

The consecutive 1-day use of PRF GON with botulinum toxin therapy may be a useful option for the treatment of refractory chronic migraine. The combined interventional procedures are effective, minimally invasive, inexpensive, safe, and well tolerated and can be performed on an outpatient basis.

\section{Limitations}

The main limitation of this study is the small sample size of heterogeneous patients, short observation period, and the absence of a comparison group. We should note that our patients were exposed to two invasive procedures therefore it might result in some placebo response distortion. Also we wish we had a larger sample size to strengthen our conclusions.

Abbreviations $B T A$, BoNT-A-onabotulinumtoxin A; $C M$, chronic migraine; GON, greater occipital nerve; $I C H D-I I$, International Classification of Headache Disorders-2nd edition; IHS 2004 HCCC, International Headache Society 2004 Headache Classification Committee Criteria; $N R S$, numeric rating scale; $P R F$, pulsed radiofrequency; $R C M$, refractory chronic migraine; RHSIS, Refractory Headache Special Interest Section

Acknowledgements We thank the participants of the study.

Author's Contribution IM perfomed procedures, collected data, and have drafted the work.

$\mathrm{AV}$ created the conception and design of the work, interpretation of data, and substantively revised it. All authors read and approved the final manuscript.

Funding No funding or sponsorship was received for this study. The Rapid Service Fee was funded by the M. Schilling GmbH, In den Kappeswiesen 18, D-63571 Gelnhausen-Hailer, Germany.

Availability of Data and Materials The datasets generated during and/or analyzed during the current study are available from the corresponding author on reasonable request. 


\section{Declarations}

Ethics Approval and Consent to Participate This retrospective study protocol was approved by the local ethics committee of the Center of Endosurgery and Lithotripsy (CELT) Moscow, Russia, in accordance with the Declaration of Helsinki.

Consent for Publication Informed written consent was provided from the patients for participation in this study and publication of these accompanying images.

Competing Interests The authors declare no competing interests.

Open Access This article is licensed under a Creative Commons Attribution 4.0 International License, which permits use, sharing, adaptation, distribution and reproduction in any medium or format, as long as you give appropriate credit to the original author(s) and the source, provide a link to the Creative Commons licence, and indicate if changes were made. The images or other third party material in this article are included in the article's Creative Commons licence, unless indicated otherwise in a credit line to the material. If material is not included in the article's Creative Commons licence and your intended use is not permitted by statutory regulation or exceeds the permitted use, you will need to obtain permission directly from the copyright holder. To view a copy of this licence, visit http://creativecommons.org/licenses/by/4.0/.

\section{References}

1. Steiner TJ, Birbeck GL, Jensen R, Katsarava Z, Martelletti P, Stovner LJ. The global campaign, World Health Organization and lifting the burden: collaboration in action. J Headache Pain. 2011;12:273-4.

2. May A, Schulte LH. Chronic migraine: risk factors, mechanisms and treatment. Nat Rev Neurol. 2016;12:455-64.

3. Headache Classification Committee of the International Headache Society (IHS). The International Classification of Headache Disorders, 3rd edition. Cephalalgia. 2018;38:1-211.

4. Lionetto L, Negro A, Palmisani S, Gentile G, Fiore MRD, Mercieri $\mathrm{M}$, et al. Emerging treatment for chronic migraine and refractory chronic migraine. Expert Opin Emerg Drugs. 2012;17:393-406.

5. Lu SR, Fuh JL, Chen WT, Juang KD, Wang SJ. Chronic daily headache in Taipei, Taiwan: prevalence, follow-up and outcome predictors. Cephalalgia. 2001;21:980-6.

6. Wang SJ, Fuh JL, Lu SR, Liu CY, Hsu LC, Wang PN, et al. Chronic daily headache in Chinese elderly: prevalence, risk factors, and biannual follow-up. Neurology. 2000;54:314-9.

7. Schulman EA, Lake AE 3rd, Goadsby PJ, et al. Defining refractory migraine and refractory chronic migraine: proposed criteria from the Refractory Headache Special Interest Section of the American Headache Society. Headache. 2008;48:778-82.

8. Kumar K. Therapeutic use of botulinum toxin in pain treatment. Neuronal Signal. 2018;2:NS20180058.

9. Do TP, Hvedstrup J, Schytz HW. Botulinum toxin: a review of the mode of action in migraine. Acta Neurol Scand. 2018;137:442-51.

10. Aguila MER, Rebbeck T, Leaver AM. The association between clinical characteristics of migraine and brain GABA levels: an explor-atory study. J Pain. 2016;17:1058-67.

11. Ramachandran R, Yaksh TL. Therapeutic use of botulinum toxin in migraine: mechanisms of action. Br J Pharmacol. 2014;171:417792.
12. Aurora SK, Dodick DW, Turkel CC, DeGryse R, Silberstein SD, Lipton RB, et al. Onabotulinumtoxin A for treatment of chronic migraine: results from the double-blind, randomized, placebocontrolled phase of the PREEMPT 1 trial. Cephalalgia. 2010;30: 793-803.

13. Diener HC, Dodick DW, Aurora SK, Turkel CC, DeGryse R, Lipton RB, et al. Onabotulinumtoxin A for treatment of chronic migraine: results from the double-blind, randomized, placebocontrolled phase of the PREEMPT 2 trial. Cephalalgia. 2010;30: 804-14.

14. Dodick DW, Turkel CC, DeGryse R, et al. Onabotulinumtoxin A for treatment of chronic migraine: pooled results from the doubleblind, randomized, placebo-controlled phases of the PREEMPT clinical program. Headache. 2010;50:921-36.

15. Sluijter ME. Pain in Europe, Barcelona. Non-thermal radiofrequency procedures in the treatment spinal pain. 2nd Annual Congress of the European Federation of IASP Chapters; 1997; p. 326.

16. Sluijter ME, Cosman ER, Rittman W III, Kleef M. The effects of pulsed radiofrequency fields applied to the dorsal root ganglion. Pain Clin. 1998;11:109-18.

17. Van Zundert J, de Louw AJ, Joosten EA, et al. Pulsed and continuous radiofrequency current adjacent to the cervical dorsal root ganglion of the rat induces late cellular activity in the dorsal horn. Anesthesiology. 2005;102:125-31.

18. Chang MC. Efficacy of pulsed radiofrequency stimulation in patients with peripheral neuropathic pain: a narrative review. Pain Physician. 2018;21:E225-34.

19. Cohen SP, Peterlin BL, Fulton L, Neely ET, Kurihara C, Gupta A, et al. Randomized, double-blind, comparative-effectiveness study comparing pulsed radiofrequency to steroid injections for occipital neuralgia or migraine with occipital nerve tenderness. Pain. 2015;156:2585-94.

20. Gabrhelík T, Michálek P, Adamus M. Pulsed radiofrequency therapy versus greater occipital nerve block in the management of refractory cervicogenic headache - a pilot study. Prague Med Rep. 2011;112:279-87.

21. Vanderhoek MD, Hoang HT, Goff B. Ultrasound-guided greater occipital nerve blocks and pulsed radiofrequency ablation for diagnosis and treatment of occipital neuralgia. Anesth Pain Med. 2013;3:256-9.

22. Martelletti P, Katsarava Z, Lampl C, Magis D, Bendtsen L, Negro A, et al. Refractory chronic migraine: a consensus statement on clinical definition from the European Headache Federation. J Headache Pain. 2014;15:47.

23. Greher M, Moriggl B, Curatolo M, Kirchmair L, Eichenberger U. Sonographic visualization and ultrasound-guided blockade of the greater occipital nerve: a comparison of two selective techniques confirmed by anatomical dissection. Br J Anaesth. 2010;104(5): $637-42$.

24. Kwak S, Chang MC. Management of refractory chronic migraine using ultrasound-guided pulsed radiofrequency of greater occipital nerve: two case reports. Medicine (Baltimore). 2018;97(45): e13127.

25. Charles A. The pathophysiology of migraine: implications for clinical management. Lancet Neurol. 2018;17:174-82.

26. Conway S, Delplanche C, Crowder J, Rothrock J. Botox therapy for refractory chronic migraine. Headache. 2005;45:355-7.

27. Butera C, Colombo B, Bianchi F, Cursi M, Messina R, Amadio S, et al. Refractory chronic migraine: is drug withdrawal necessary before starting a therapy with onabotulinum toxin type A? Neurol Sci. 2016;37:1701-6.

28. Palma JA, Irimia P, Fernandez-Torron R, Ortega-Cubero S, Riverol $\mathrm{M}$, Luquin MR, et al. Clinical experience of treatment with 
onabotulinumtoxin A in patients with refractory migraine. Rev Neurol. 2012;54:705-11.

29. Dressler D. Clinical presentation and management of antibodyinduced failure of botulinum toxin therapy. Mov Disord. 2004;19 Suppl 8:S92-S100.

30. Naumann M, Carruthers A, Carruthers J, Aurora SK, Zafonte R, Abu-Shakra S, et al. Meta-analysis of neutralizing antibody conversion with onabotulinumtoxin A (BOTOX®) across multiple indications. Mov Disord. 2010;25:2211-8.

31. Li J, Yin Y, Ye L, Zuo Y. Pulsed radiofrequency of C2 dorsal root ganglion under ultrasound guidance for chronic migraine: a case report. J Pain Res. 2018;11:1915-9.

32. Manolitsis N, Elahi F. Pulsed radiofrequency for occipital neuralgia. Pain Physician. 2014;17(6):E709-17.

33. Palamar D, Uluduz D, Saip S, Erden G, Unalan H, Akarirmak U. Ultrasound-guided greater occipital nerve block: an efficient technique in chronic refractory migraine without aura? Pain Physician. 2015;18:153-62.

34. Inan LE, Inan N, Karadaș Ö, Gül HL, Erdemoğlu AK, Türkel Y, et al. Greater occipital nerve blockade for the treatment of chronic migraine: a randomized, multicenter, double-blind, and placebocontrolled study. Acta Neurol Scand. 2015;132:270-7.

35. Saper JR, Dodick DW, Silberstein SD, McCarville S, Sun M, Goadsby PJ, et al. Occipital nerve stimulation for the treatment of intractable chronic migraine headache: ONSTIM feasibility study. Cephalalgia. 2011;31:271-85.

Publisher's Note Springer Nature remains neutral with regard to jurisdictional claims in published maps and institutional affiliations. 